\title{
Challenges, Opportunities and Innovations Faced by the Broadcasting and Hosting Industry in the Era of Convergence Media
}

\author{
Xueyan Zhang \\ School of Media and Arts, Shanghai University of Sport, Shanghai, China \\ Email: dchzhang2007@163.com
}

How to cite this paper: Zhang, X. Y. (2021). Challenges, Opportunities and Innovations Faced by the Broadcasting and Hosting Industry in the Era of Convergence Media. Advances in Journalism and Communication, 9, 102-113.

https://doi.org/10.4236/ajc.2021.93008

Received: August 3, 2021

Accepted: August 29, 2021

Published: September 1, 2021

Copyright $\odot 2021$ by author(s) and Scientific Research Publishing Inc. This work is licensed under the Creative Commons Attribution International License (CC BY 4.0).

http://creativecommons.org/licenses/by/4.0/

\section{(c) (i) Open Access}

\begin{abstract}
Analyzes the challenges and opportunities facing the broadcasting and hosting industry in the era of fusion media from the perspective of audience, host personality and media discourse power. According to the research, with the advent of the era of integrated media, the broadcasting and hosting industry is faced with the impact and challenges brought by the diversification of audience choice, the weak personality of broadcasting and hosting, the transformation of media discourse power and the rapid development of artificial intelligence. However, it also faces the development advantages and opportunities brought by increasing audience, expanding influence, direct communication effect, prominent audience literacy, and modern media technology change. Put forward the innovation old thinking and concept of broadcasting and hosting, set up personalized style of broadcasting and hosting, improve the level of business of broadcasting and hosting, use new media technology innovation, and expand the media culture communication ability and so on industry innovation and development countermeasures of broadcasting and hosting. Finally, the future development prospect of broadcasting and hosting industry in the era of fusion media is prospected.
\end{abstract}

\section{Keywords}

Convergence Media, Broadcast Hosting, Challenge, Opportunity, Innovation

\section{Introduction}

Convergence media era is a new media and traditional media era of a variety of media mutual convergence. Compared with the previous communication effect, the era of converged media has greatly expanded the original communication 
channels and greatly enhanced the influence of communication. New media can make full use of mobile Internet technology and release simultaneously through a variety of platforms and means, presenting the characteristics of real-time, fast, multi-direction and strong interactivity, which greatly improves the speed of information transmission. At the same time, new media technology is more abundant in the form of expression, including text, image, sound, real-time video, etc., and can carry out personalized combination of various information components, which can not only effectively improve the quality of information transmission, but also can greatly improve people's feelings and acceptance of new media. "Converged media" is a new media that uses media carriers to integrate the resources of complementary media such as radio, television and newspaper in a certain way. The emergence of this new media changes the way people transmit and receive information. The broadcasting and hosting industry of traditional media is no longer the only subject of information transmission. The sense of crisis in the broadcasting and hosting industry in traditional media is constantly enhanced. In the era of integrated media, broadcasting and hosting are faced with great challenges as well as great opportunities (Wei, 2019).

The emergence and development of new media have formed a new pattern of media communication. The Internet is the fourth-largest media after newspapers, radio and television. The advent of the Internet has ushered in a new era for human information transmission (Yao, 2013). The development of Internet technology drives the strong rise of emerging media, smartphones, mobile computers and other portable communications equipment almost modern society must-have social tools, with the aid of these tools to spread information website, Micro-blog, WeChat public platform, mobile clients, such as port appeared, and launch video, new media broadcast host arises at the historic moment. The new media broadcasting and hosting has changed the content and way of information transmission, and the innovative, stylized and diversified hosting style has brought unprecedented opportunities and challenges to the traditional media broadcasting and hosting.

The origin of broadcasting and hosting art depends on traditional media. Whether it is broadcasting and hosting practice or theoretical research, it ultimately reflects and adapts to the constantly evolving social needs and social practices (Jing, 2016). Social need and social practice are the premise of broadcasting and hosting practice and the source of broadcasting and hosting creation. The art of broadcasting and hosting is closely related to the development of The Times. The art of broadcasting and hosting keeps pace with The Times is related to the quality and effect of communication, so it should actively integrate into and adapt to the new trend of The Times of communication.

Media technology development, the entire media, holographic media, the media, the full effect of the whole media becomes a trend, leading to ecological public opinion dissemination way, the media landscape, profound changes, such as using all aspects of the media for video, audio, text, images, etc. Various media forms at the same time the spread of the convergence media arises at the historic 
moment, and become the new trend. To a certain extent, the broadcasting host plays an irreplaceable role in the dissemination of information. At the same time, it is inevitably impacted by the growing strength of other media. Therefore, under the situation of both challenges and opportunities, the innovation of broadcasting and hosting has become an inevitable trend (Cao, 2018).

\section{The Convergence Media Age the Challenge for the Industry of Broadcasting and Hosting}

\subsection{Diversified Choices of Audiences}

First, in the era of converged media, great changes have taken place in the way that audiences obtain information. They no longer rely on traditional media such as newspapers, radio and TV, but choose suitable media according to their actual needs to pay attention to and obtain information. British communication scholar Danny McGuire believes that in the current communication era, the audience is a special public who can choose themselves, and individual information needs are personalized. Therefore, the needs of audiences in the era of converged media are "customized". New media can learn information anytime and anywhere through pictures, text, audio and video, etc. Audiences are more flexible in choosing information sources, which has a huge impact on traditional media such as radio and television (Wang, 2017).

In this situation, the presenters face the following pressures: 1) Although the era of converged media has promoted the progress of traditional media, it uses advanced technology and broad perspectives; In addition, the development of science and technology has improved People's Daily life. Most people have abandoned the way to get news from traditional media such as TV, and smart phones and computers have become the mainstream platform for information acquisition; 2) The era of convergence media is characterized by a wide range and diverse content. It enables people to independently search the news content they need according to their interests and hobbies on new media platforms such as the Internet and Micro-blog, greatly enhancing efficiency. Compared with traditional TV news, although it is accurate and authentic, it takes more time for people to search, so most people choose to use new media to obtain information.

\subsection{The Personalization of Broadcasting and Hosting Is Not Significant}

In the past, with TV media as the mainstream news media platform period, a lot of TV news programming rut, more than ten years, television's consistent report way, lack of innovation, the broadcasting television reports are written in advance, blunter the official language, to give the audience a kind of serious, inflexible impression, In the new media broadcasting and hosting staff humorous hosting style contrast, the kind of no characteristics, uniform broadcasting and hosting style in the market competition is easy to lose the opportunity.

Mobile Internet technology makes the communication environment highly 
open and interactive. The concept of Internet is constantly updating the content and form of broadcasting and hosting. The field of broadcasting and hosting from the traditional "I play you listen" to open hotline, interactive communication. In the era of harmonious media, the broadcast host should not only embody the solemn temperament and expression norms of information authority, but also have the personality characteristics of easy-going and enthusiastic. For example, compared with new media, the environment of traditional broadcasting and hosting is more professional and independent. Due to the particularity of broadcasting, the broadcasting of broadcasters is required to be serious and authoritative, and the way of hosting is also more formal, which limits the style and characteristics of broadcasters to a certain extent. New media style is diverse, personalized, more in line with the modern public taste. However, the complexity and particularity of the TV news production process also lead to the single style of the TV news broadcast workers without their own characteristics, and the degree of individuation is not high.

\subsection{Transformation of Media Discourse Power}

The authority of traditional media industry can lead the trend of social public opinion to a certain extent, so that the broadcasting host has a certain right of discourse. However, nowadays, in the era of integrated media, there are various ways for the public to obtain and transmit information, and the importance of news anchors is not as great as before, which leads to the transformation of their discourse power. In addition, the development of science and technology network, diversified and popular slowly become the characteristics of the modern news content, news content to contact people in real life growing, audience present a tendency of increasing the degree of attention to news, participate in consciousness constantly strengthen, broadcasting workers say slowly into the audience, and thus to some extent influence the development of the traditional media industry.

Among the three traditional media giants, namely print media, radio and TV, TV media is the most closely connected with the audience. During the period when TV media "monopolized" the news broadcasting and hosting industry, TV news broadcasting and hosting hosts have a very high right of discourse in news communication through long-term cooperation with the vast audience. However, with the advent of the era of converged media, the influence of this kind of discourse is gradually weakened. The rapid popularization of the Internet makes the audience invest in the new media environment in a relatively short period of time, instead of just listening to the comments and explanations of TV news anchors, and they have some freedom of comment within the scope of the law, and even can release the news independently. In today's society, the pace of people's life is getting faster and faster. Most people do not have the time and patience to watch news programs in front of the TV, but prefer the "fragmented" news information that they are interested in. Therefore, short news on the network is more in line with the reading needs of modern people. The new media 
play more and more influence in the audience's life, at the same time, the discourse power of TV news announcers is decreasing.

\subsection{Changes in Job Demand Caused by Artificial Intelligence}

In 2018, at the fifth World Internet Conference in Wuzhen, China, the world's first fully simulated intelligent synthetic host was presented, thus setting off a wave of hot discussion on artificial intelligence. In the future, in the field of basic information broadcasting of some media, intelligent robots will be widely used because of their high work efficiency and low human cost, and professional information broadcasting positions of broadcasting and hosting will be impacted. On the other hand, due to the breakthrough of new technology, media programs will be more high-tech to present the content, a large number of program content because of the support of high technology, to achieve the expansion of space, the role of the announcer is not as important as before, the hosting space has been reduced and compressed. Every media announcer and host must face the impact and challenge of the change of communication mode, personal life and work experience.

\section{Opportunities Facing the Broadcasting and Hosting Industry in the Era of Converged Media}

Broadcasting and hosting is a strong sense of The Times of the occupation, practical, high attention and high professional standards. It can be said that shocks and challenges are the norm in this profession. From the era of "preaching" and "broadcasting" to "open live communication", the quality test of announcers is also from broadcast with draft to broadcast without draft, and adapt to hot line communication and cope with it freely. Change is permanent; Invariant is temporary. The broadcasting and hosting industry is facing great challenges as well as great opportunities.

\subsection{The Audience Increases and the Influence Expands}

The American online magazine defines new media as "the spread of everyone to everyone". In the application of new media, the competition among communicators is fierce, but the communication effect also expands accordingly and is omnipresent. Many radio and television hosts expand the audience with the help of new media, and open public accounts to carry out multi-channel, matrix, and all-directional communication that can be heard and seen. In addition to the main position of broadcast, but also through WeChat public account, Micro-blog, mobile phone client and other platforms across the screen dissemination.

Convergence media is a kind of self-renewal media under the background of information age, the result of the coordinated development, is based on the rapid development of Internet information data, the value of resources, the high degree of integration operation pattern, the concept of technology of iteration and updates, as well as the huge change of media environment, reshape the occupation- 
al role function of broadcasting and hosting. By January 2018, the number of new media users of CRI had reached more than 300 million, with an average daily audience of over 32 million. In such an interaction, the scene more mass production stage, in the form of voice of artificial intelligence and virtual host professional, deepening the cognition to the field of denotation and connotation of broadcasting and hosting, also for professional talents of broadcasting and hosting core skills, high quality transmission of language communication, space specification and purification, industry professional, etc. put forward more requirements.

\subsection{Direct Effect and Prominent Accomplishment}

Compared with traditional media, new media and "we-media" in integrated media communication have the advantages of instantaneity, interactivity, openness, individuality, mass information, unlimited communication, low cost, convenient search and so on. Among them, the digitization of information processing technology and the interactivity of communication mode are the most essential characteristics, with high communication efficiency and wide communication fields. The rapid spread of new media and "we-media" makes people deeply feel the effect and power of network media. However, since the disseminators are mostly ordinary people, the authority and accuracy of information dissemination are weak, and the information has to go through the process of inversion and inversion. However, broadcasters and hosts in traditional media have a solid foundation brought by professional training in policy level, ideology, communicational propriety and language essence. In the process of communication, the processing of communication information is more in line with the social trend, ideology, audience needs, ethical values and social development, which can't be compared with we-media communication without professional training.

"China New Media Development Report (2018)" showed that the continuous return of content value has become a new hot spot for the profit growth of new media. Reports that present objective facts and in-depth information are particularly valuable. Although new media information bombing because fresh and mass audience dazzled, but in the future with the mature of the audience, and the contents and the return of the value idea, believe that the traditional media announcer host quality advantages and mature personality kernel will gradually stand out in the era of widely spread, the spread of the convergence, and is becoming more and more outstanding.

\subsection{Actively Respond to Technological Change}

Modern media is a field that is directly influenced by technology, and technological innovation has brought about earth-shaking changes in communication styles. From the "Internet of everything" to the "intelligence of everything" era, not only the traditional media is impacted in the change, the value of human itself will be challenged by artificial intelligence in the future. The key to converged 
media is technological change. Serving the public through technology is the system engineering of the future media.

Senior media people, especially broadcasters and presenters, are deeply impacted, and it is their duty and mission to face and cope with changes. In the process of human society developing to artificial intelligence, everyone can't avoid the integration of technology into life and work. As long as broadcasters and presenters who have the basis of media literacy and have inherited the advantages of media social communication can timely supplement and make good use of technical knowledge, they can better adapt to the new era by integrating media through Unicom before the advent of the era of comprehensive artificial intelligence.

\section{Reform and Innovation of Broadcasting and Hosting Industry in the Era of Convergence Media}

\subsection{Innovate the Outdated Thinking and Concept of Broadcasting and Hosting}

The template since entering the era of "everyone is from the media", TV news programs are in a state of existence between traditional media and new media. Objectively, it requires related broadcast hosts to update their working thinking in time to meet the requirements of diversified information dissemination. At the same time, the era of convergence media greatly expands the channels of information transmission, greatly improves the transmission of TV news programs, and improves the individual influence of the announcers. In addition to basic work qualities, broadcast hosts must keep up with the era of integrated media, put forward higher ability requirements for their own positions, and make their abilities match the TV news programs in the new era. At the same time, during the dissemination of news and information, broadcast hosts should have the courage to explore their own thinking, be good at giving play to the technical advantages of new media, and highlight the communication value of new media, such as using WeChat public account to strengthen the interaction with the audience, etc. (He, 2017).

Under normal circumstances, whether a TV news program with distinct themes and sufficient content can attract the attention of the broad audience depends to a large extent on the host's own charm, which is reflected in the charm of knowledge transmission. At the same time, the highly active broadcast hosts in the major "we-media" tend to be knowledgeable and have a broad vision. In a real sense, they can meet the audience's demand for more information, and help the audience no longer stay at the stage of understanding the surface meaning, but thoroughly understand the content of news information. Therefore, TV news broadcasting and hosting must continue to innovate the dissemination of ideas, constantly strengthen self-learning, improve their professional quality, give full play to their own charm, attracting more audience's attention. In addition, when disseminating news and information, they should take the lead in understanding 
its content, and then carry out reasonable and effective communication based on their theoretical knowledge and the needs of the audience.

\subsection{Establish Personalized Broadcasting and Hosting Style}

Television news programs generally require seriousness, but seriousness is only the principle it needs to adhere to, which does not prevent the broadcasting and hosting to carry out the seriousness principle as the prerequisite for appropriate innovation. At the same time, information dissemination in the era of converged media is no longer confined to the one-way level, but presents a two-way interactive development direction (Cao, 2019). Therefore, in the process of practical innovation, related to television news should be to ensure the accuracy and timeliness of information transmission of broadcasting and hosting the premise condition, timely attention to audience's own ideas, initiative and the audience, communication between each other to form a good and stable information share model, and continue to weaken its own high above the external image, actively cater to the development characteristics of the era of convergence media, combined with broadcast content to continue to innovate their own broadcasting and hosting style, in a real sense to achieve the dissemination of news information based on the audience.

Under the mode of convergence media, the development of broadcasting and hosting has a trend of minority. Many programs are popular with the audience, which is because the broadcasting personnel present their own style, that is to say, it must have personalized characteristics, to be able to attract different levels of audience. Different broadcasting and hosting personnel have different styles, which are reflected from the expression habits, physical features, personal temperament and accomplishment. As the broadcasting and hosting practitioners, first of all, we should change our own language image, from the tone, intonation, speed and other aspects of transformation, to create a personalized voice image. Secondly, image, posture, gestures and other paralanguage, is also essential, must form a unique personal style. Thirdly, it is the appearance characteristics, according to their own actual situation, choose the appropriate clothing collocation, and in line with the positioning of the program. Finally, personal temperament and personal values can be cultivated through reading, painting, calligraphy and other ways to cultivate their own sentiment, artistic accomplishment, from the inside out to send out a unique temperament. In the process of improving their ideological and moral cultivation, they have a correct judgment of things.

\subsection{Improve the Service Level and Emergency Handling Ability of Broadcasting and Hosting}

Media integration brings the development of faster information transmission, the announcer and host has a higher capacity requirements in information processing, in the news, try to use simple language to describe the news events, on-site in oral form, at the same time pay attention to the audience the most concern, especially the scene, events, and the reaction of the parties, In order to meet the audience 
and audience to news information timeliness of the request. In the era of media convergence, hosts can perform live broadcasts using only a mobile phone. Such a state is also a test of the all-round professional ability of the host. Therefore, the host should consider how to make his mobile live broadcast more attractive to the audience. Compared with the sound of TV broadcast, mobile broadcast needs more sense of humor and more self-expression, especially for some relatively serious topics, which need younger ways of expression.

How to deal with emergencies is also a new topic that many broadcasting hosts may face in the era of converged media. All things happen suddenly. If the broadcasting staff do not have strong psychological quality and strain ability, they will not be able to deal with these problems in an orderly way, which will affect the effect of the whole program. Therefore, the broadcasting and hosting personnel, first of all, is to exercise a leisurely state of mind. Once an emergency occurs, it should be handled calmly and calmly. Every broadcasting and hosting personnel should respond intelligently and use their own expression ability to deal with the occurrence of an emergency. If the emergency treatment is proper, maybe it will become a surprise and thrilling, received unexpected dissemination effect, to add luster to the program. In the era of integrated media, the broadcasting host must make continuous progress. Constantly improve their business ability and the ability to deal with emergencies if they want to make rapid transformation.

\subsection{Innovation by Using Converged New Media Technology}

The integrated media network platform makes the program live online and strengthens the interaction and contact between the broadcast host and the audience, so as to get the latest suggestions from the audience in time. During the broadcast, the audience makes comments or asks questions through the barrage, and the host receives the relevant information on the spot, and then gives a timely answer or explanation. In addition, many programs will have a lottery when they are broadcast. After certain conditions are set, the audience will be attracted to participate in the lottery actively, so as to strengthen the interaction with the audience. This interactive process can be accomplished through the combination of new media and traditional media. When the host will own hosting style into the program, in the continuous interaction with the audience, it itself has become a part of the program, the host of the program as a whole is more complete and coordinated.

Convergence media era, "cloud computing" and some voice messages broadcast by AI robots replace has become an inevitable trend, a large number of intelligent synthetic voice convenient information mass communication anytime and anywhere, but the human emotion subtle delicate changes, as well as embody humanistic feelings and cultural charm of art, Robots are difficult to grasp perfectly because of the virtual nature of their emotions. Journalism and Communication, art, linguistics and applied linguistics, literature, psychology and philosophy, aesthetics and many other disciplines. The core advantage of the discipline lies in the mastery of language, the training of emotional expression, and the 
profound presentation of high-end language art. The exquisite emotional enjoyment provided by elegant language arts such as recitation, and the ability of anchors to accurately comment on complex news events in news comments are the salient features of broadcasting and hosting artistic talents, and also the core advantages of broadcasting and hosting artistic talents that distinguish them from intelligent language tools. Traditional media announcers and hosts should strengthen their professional characteristics and improve their professional quality in quality training, so as to realize the high-quality communication ability of talents in the era of integrating media, which is one of the important strategies for the broadcasting and hosting profession to achieve innovation in the era of integrating media and artificial intelligence.

\subsection{Expand the Cultural Communication Capacity of All Media}

The era of converged media is also the era of digital media. A series of new technologies such as Web2.0, P2P technology, broadband technology, streaming media technology and wireless communication are becoming increasingly mature and combined with each other, providing possibilities for information exchange and sharing between individuals and between media. The identities of communicators and audiences are changeable and interactive. Audiences no longer passively accept information, but actively grasp and control information and participate in the dissemination of information.

Contemporary American political scientist Samuel Huntington (Samuel, 2013) put forward the "clash of civilizations" view, according to this view, culture is single, there is competition, if a culture can "rise", and the country can win in the competition. British communication scholar Dennis McGuire believes that the audience is no longer a part of the public, but a self-selected network member, a special public, or an individual. In this case, the needs of the audience tend to be personalized and interactive, and there are internal needs and external possibilities for personalized customization of information and communicators. Such interactive communication and personalized needs require broadcasters and hosts to quickly adapt to and increase their personalized communication capabilities, interactive capabilities and live broadcast capabilities, so as to form a comprehensive expression and communication capability with all-media hosts as the core (Liang, 2019). As long as traditional broadcasters and presenters keep pace with The Times in the era of integrated media, actively learn and master the use of modern communication technology, and adhere to the truth seeking, good and beautiful content of communication, the future development path will be very broad.

\subsection{Suggestions for the Future Development of the Broadcasting and Hosting Industry}

Mobile Internet technology has changed the way people get news information, for the long-term, healthy and sustainable development of media industry has a 
profound impact. At the same time, new media technologies, including artificial intelligence, are widely used in the field of broadcasting and hosting, and announcers and hosts need to constantly improve their professional level and literacy. So, faced with the challenge of new media technology, on the one hand, the announcer host in the program of performance forms, should make full use of new media technology, the sound, image, text and other information personalized elements that composed the combination, on the other hand, the announcer host to continuously strengthen, on the basis of individual learning, improve personal accomplishment, Form irreplaceable unique hosting style.

Today, increasingly competitive media industry, the importance of interactive of broadcasting and hosting is also increasingly apparent. After the application of new media technology to radio and television broadcasting and hosting, not only the quality and efficiency of information release have been greatly improved, but also the direction of information transmission has changed, making the information transmission into two-way interaction, or even multi-directional sharing. Therefore, in the broadcasting and hosting process of radio and television, interactive broadcasting mode can be used to realize the interaction between the host and the audience through the network, telephone, WeChat, Micro-blog and other ways. This can not only effectively improve the effect of broadcast and television broadcasting, but also greatly increase people's affinity and acceptance of broadcast and television broadcasting. Media convergence is the mainstream of the media industry development. Radio and television industry must seize this development opportunity, make full use of new media technology, and actively reform and transform towards the direction of modernization.

\section{Conclusion}

Media convergence is not only the integration of strategy and technology but also the transformation and integration of thinking and concept. In the era of media convergence, new media "strong rise", websites, WeChat, Mobile clients have launched video programs, and have their own hosts. The convergence of media not only changes the media environment but also brings audience differentiation, information reception and communication content changes, etc. Traditional media broadcasting and hosting, especially TV news broadcasting and hosting, are facing challenges and opportunities brought by the diversification, stylization and innovation of new media.

The rapid development of information technology has brought unprecedented changes to the world. It is a realistic problem that the broadcasting and hosting industry must face to actively meet the challenge, seek impetus in the pressure and seek opportunities in the challenge. Industries need to address audience shunt, program of broadcasting and hosting platform upgrade, change the traditional way of broadcasting and hosting, artificial intelligence and post to demand change, challenge and impact, build confidence, dig new media age audience and the influence of the huge advantages, catch the opportunity of communication effect 
directly, highlight their literacy, actively spread into new technology environment. In terms of coping strategies, we should objectively face the changes, strengthen professional characteristics, improve professional quality, pay attention to the changes in communication needs, and enhance and expand the ability of all-media communication. It is believed that in the new era of converged media, the broadcasting and hosting industry will definitely have greater innovation and development.

\section{Conflicts of Interest}

The author declares no conflicts of interest regarding the publication of this paper.

\section{References}

Cao, L. J. (2019). New Media Era TV News Broadcast Management and the Development of All Creation. Reporter Cradle, 3, 93-94

Cao, Y. P. (2018). All Media Era TV News Broadcast Hosted the Challenge and Countermeasures. Research on Communication Power, 2, 123-129

Zhen, C. H., \& Huang, Y. N. (2018). China New Media Development Report (2018): New Technology Speeds up Media Convergence. China Press and Publication Radio \& Telegraph. http://media.people.com.cn/n1/2018/0703/c40606-30111254.html

He, G. (2017). The Strain and Persistence of Hosts in the Era of Financial Media. China Newspaper Industry, 24, 74-75.

Jing, C. J. (2016). An Introduction to the Art of Broadcasting and Hosting. The Communication University of China Publishing House.

Liang, Y. (2019). On The Innovation and Persistence of TV News Broadcasting in the Era of Convergence Media. Research on Communication Power, 3, 143.

Samuel, H. T. (2013). The Clash of Civilizations. Xinhua Publishing House.

Wang, D. (2017). New Media Era TV News Broadcast Management Problems and Solutions. Journal of Audio-Visual, 12, 108-109.

Wei, H. (2019). The Innovation and Persistence of TV News Broadcasting and Hosting in the Era of Convergence Media. China Newspaper Industry, 10, 95-96.

Yao, X. S. (2013). New Media Era Broadcast Television Language Study. Language Publishing House. 